Article

\title{
Cutting components by laser for cushion airbags in functional aspect
}

\author{
Zbigniew Mirski ${ }^{1 *}$, Jakub Kwiecieńn ${ }^{1}$ Jan Hejna ${ }^{1}$ \\ 1 Wrocław University of Science and Technology, Poland \\ Jakub Kwiecień; j.kwiecien.info@gmail.com \\ Jan Hejna, Ph.D. D.Sc.; jan.hejna@pwr.edu.pl \\ * Correspondence: prof. Zbigniew Mirski; zbigniew.mirski@pwr.edu.pl
}

Received: 08.10.2019; Accepted: 06.12.2019

\begin{abstract}
The airbags are one of the most important element in the vehicle, they keep people safe during accident or collision. The materials which are used to produce airbags must comply with many rigorous requirements The main aspects pertain in the article are:

- dependence between layout of fibre in the cutting material and the mechanic durability;

- airbags match elements for laser cutting facilitation;

- starts to create the laser emplacement for textiles cutting;

- laser cutting parameters of airbags elements (parameters of laser beam, cutting speed, the number of cutting layers);

- the influence of material quality for cutting effects;

- cutting materials shape tolerance and their impact on the airbag's functionality;

- quality control of cutting elements and their separation.
\end{abstract}

Keywords: laser cutting; cushion airbags; cutting quality

\section{Introduction}

Today, laser cutting is one of the most effective technologies for cutting various materials $[1 \div 8]$. Most often this applies to steel and metal components and their alloys, but also to non-metallic materials. The cut elements must meet many requirements, including requirements regarding cutting accuracy and

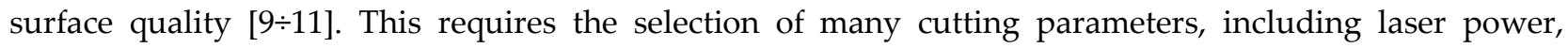
cutting speed, distance between the laser nozzle and the surface of the material being cut, type of gas shield and gas flow rate accompanying the laser beam. The components of airbags are also cut with a laser beam [12], although there are few reports on this subject in the scientific and technical literature. In the case of cutting out airbag elements, the number of process parameters is smaller, as laser cutting is usually carried out without an additional gas shield, under the influence of atmospheric air. During cutting the laser beam melts the edges of the fabric, protecting them from fraying, however, excessive melting of the edges of the multilayer fabric causes their unfavorable sticking.

People traveling in modern passenger cars are protected by many security systems, but one of the oldest and still irreplaceable elements of vehicle equipment are airbags. The textile part of the airbag module absorbs the impetus with which a person hits an airbag. The complexity and size of the cushion depends

on the requirements of the car manufacturers and the country's legal regulations, but each airbag in the vehicle has one important task: to save lives. Hence, the quality of cutting out airbag elements is of great importance here.

\section{Characteristics of textile materials and their parameters}

The process of creating an airbag begins with the extrusion of nylon fibers, which in a subsequent process are combined into threads and then woven into a material. The weaving of the material is very diverse. When weaving the material, the threads are divided into warp and weft, which is the term for the position of the thread when weaving. The vertical fibers are the warp and the horizontal fibers are the weft (Fig. 1). Depending on the position of the cut element on car airbags, its orientation relative to the warp and weft 
is blocked, thanks to which the element acquires various properties. The main property of the material is its mechanical strength, which is very important during the explosion of a pyrotechnic agent. If the element is turned $45^{\circ}$ relative to the warp and weft, a much more durable material is obtained than about $90^{\circ}$. This significantly affects the performance of the material, which also leads to an increase in the price of the product.

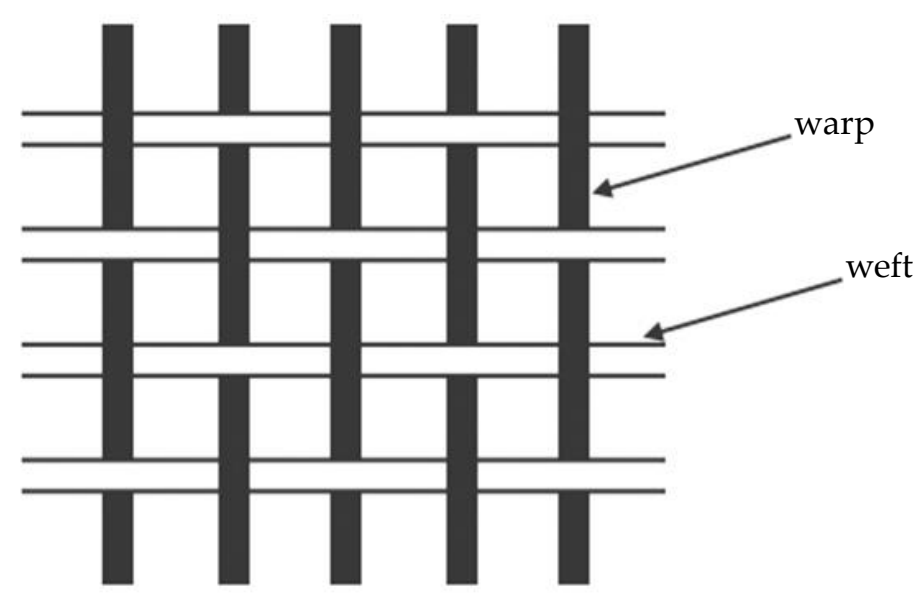

Fig. 1. Warp and weft of fabric [13]

For the production of airbags, three types of woven nylon material with 235dtex, 470dtex, 750dtex markings are most often used (Fig. 2). The dtex symbol defines the mass of fibers expressed in kilograms per $1 \mathrm{~km}$ of material. In addition, to improve the material's resistance to fire arising during an explosion of pyrotechnic material (called an inflator), silicone coating is used on one side of the material or in some cases on both sides. Depending on the need for protection against hot gas pumping the cushion at the moment of explosion, coverings are used: 25,50 or $70 \mathrm{~g}$ of silicone per $1 \mathrm{~m}^{2}$.

In the product development department, the components of airbags, according to customer needs, are designed and adjusted by structural engineers. Sewn cushions in prototype phases are checked and tested so that they can be put into serial production in the next phase of the project. Thanks to the cooperation of the maintenance departments, cutting process engineers and construction engineers, the preferred shapes of blanks have been developed that affect the efficiency of work and improve the efficiency of the cutting process by eliminating too much material waste. The most preferred shapes of cut elements are: squares, rectangles and hexagonal figures. Due to their properties, these elements have a very low material waste rate, and technological transitions between the elements are smooth and do not require turning off the laser beam. Circles and figures with rounded vertices are less preferred. Often, elements are added between such shapes that will fit into the free spaces between them. In the case of less preferred shapes of elements, the waste of material increases, and due to the time of technological transition from element to element, the laser must be turned off and then turned on. This generates large losses of electricity and causes a slight melting at the place of laser activation.

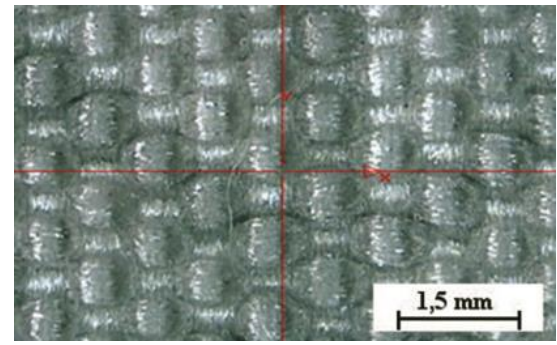

(a)

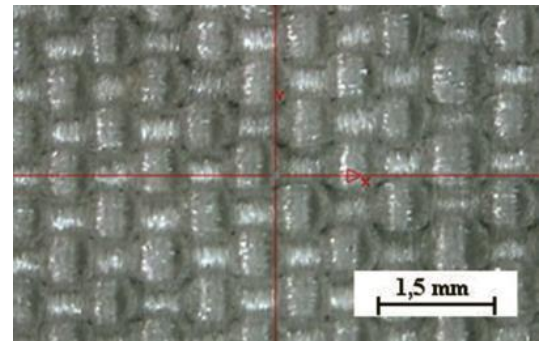

(b)

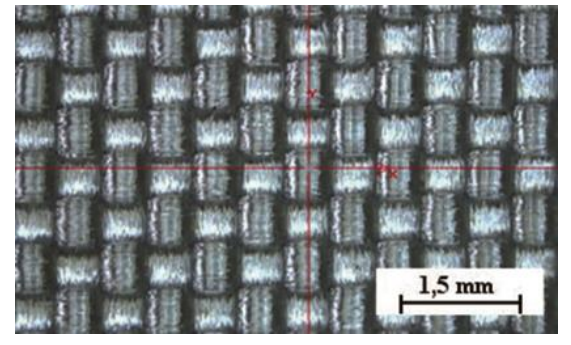

(c)

Fig. 2. a) Fabric 235 dtex, b) fabric $470 d$ tex, c) fabric 750 dtex

\section{Stand for laser cutting and basic cutting parameters}

At Autoliv Polska Sp. z o.o. with the branch located in Oława there are two types of machines for laser cutting of textile materials [14,15]. Suppliers of laser cutting combines are HELD and LANCET as well as ROFIN SINAR (1500 $\div 2500 \mathrm{~W}$ generators, molecular lasers of $\mathrm{CO}_{2}$ type). The layout of the positions where 
material for airbag elements is cut is identical, regardless of the type of machine. These areas can be divided into three zones: a material feeder, a material cutting zone and a readv-made part collection zone (Fig. 3).

Material cutting zone

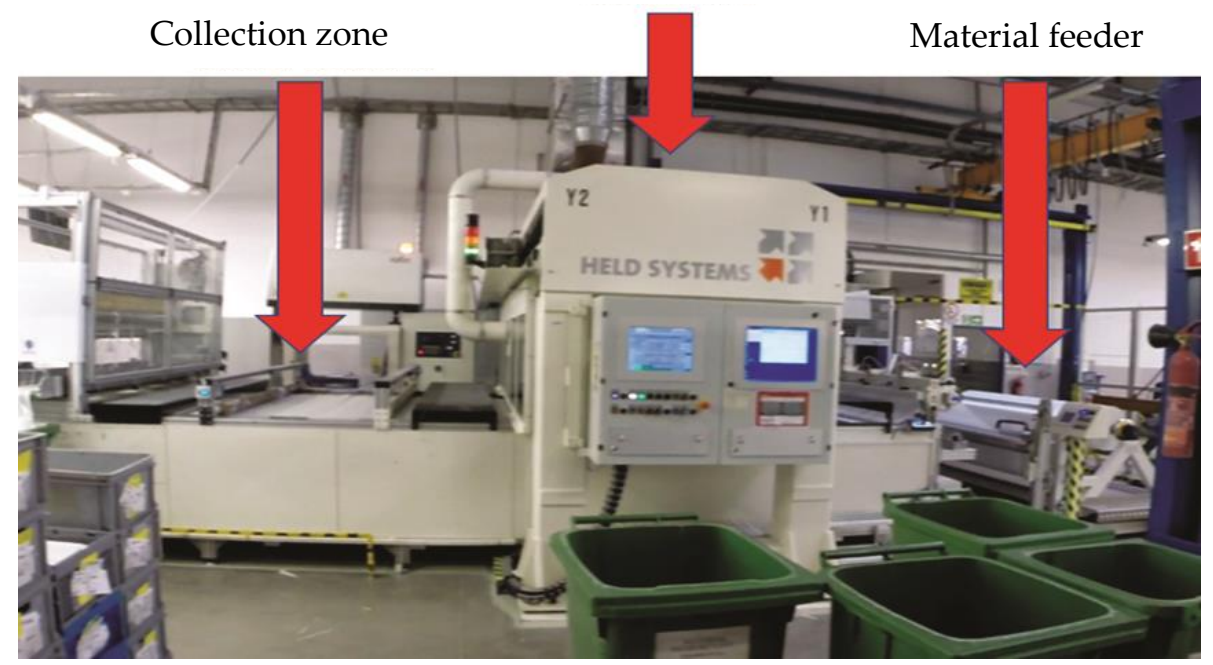

Fig. 3. Laser cutting machine

In the material feed zone, the fabric wound on a roll is passed towards the zone in which the given shapes of elements are cut out. For many machines, to increase the efficiency of the cutting process, multiple layers of material are cut simultaneously. Thanks to the feeders, up to 10 layers of material can be cut out at the same time (Fig. 4).

The material cutting zone can be divided into two types: plotter cutting and scanner cutting. For Lancet FATBOY 1000 machines, the plotter cutting method is used (Fig. 5). The specificity of this method is based on one laser beam directed at the material cut at an angle of $90^{\circ}$. The range of movement of the laser beam at the cutting station is from 0 to $2550 \mathrm{~mm}$ in the $\mathrm{x}$ axis and from 450 to $610 \mathrm{~mm}$ in the $\mathrm{y}$ axis. This range was chosen due to the variety of cut elements and for reasons of servicing the machine. The focal surface of the laser beam is $0.2 \mathrm{~mm}^{2}$, which allows cutting elements with high precision.

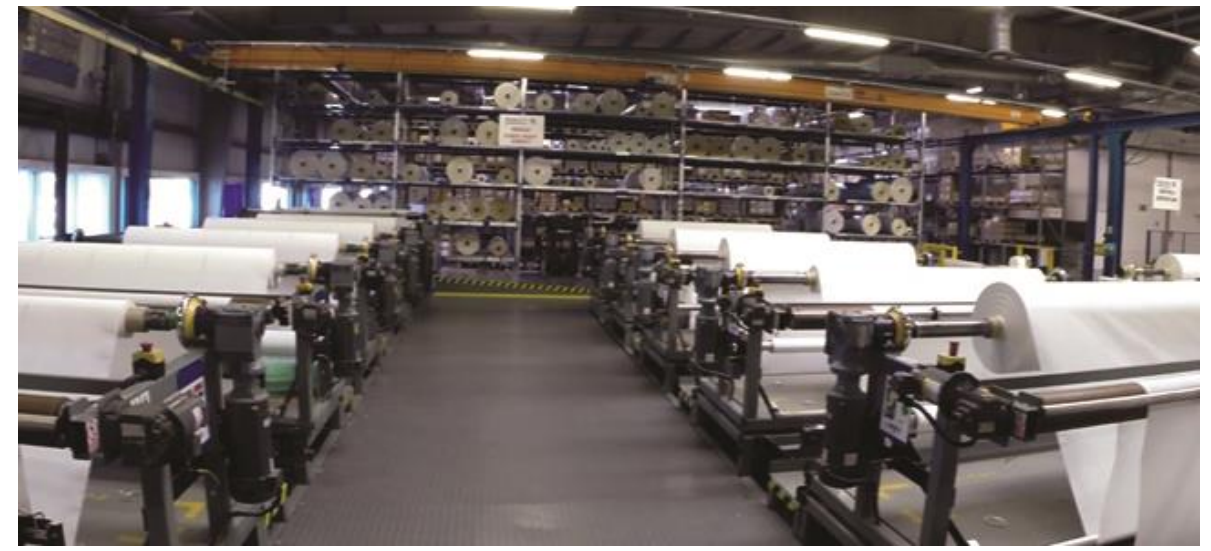

Fig. 4. Feeder of many fabric layer for cutting 


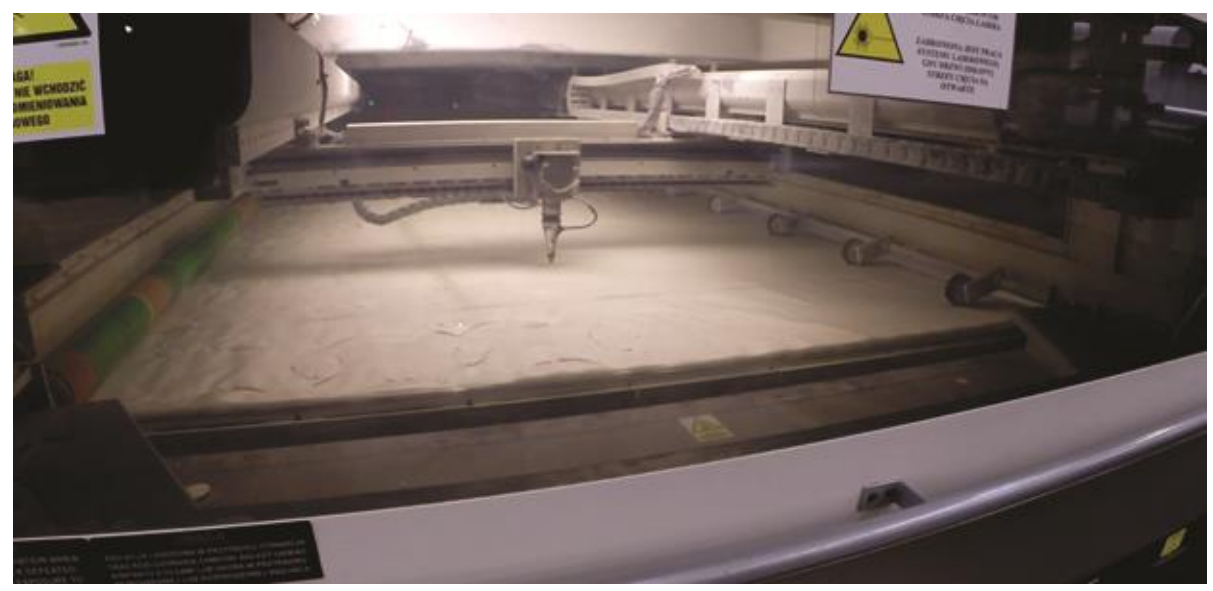

Fig. 5. Lancet FATBOY 1000 method of plotter cutting

When cutting with a plotter method, the start/stop system is distinguished, when cutting shapes it results in switching off the laser beam for one thousandth of a second and switching it on again when the laser beam reaches one of the points on the contour of the element. This is due to the creation of components using many individual lines arranged in one polyline. The most favorable for laser life and cutting time is the shape of the element consisting of the least number of lines, so that the laser turns off as few times as possible (Fig. 6).

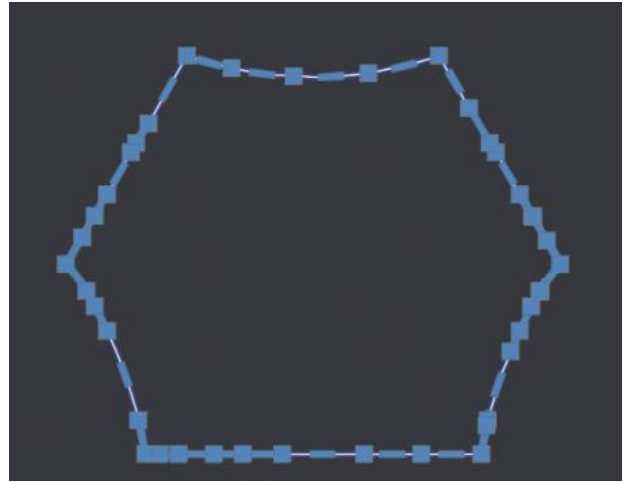

(a)

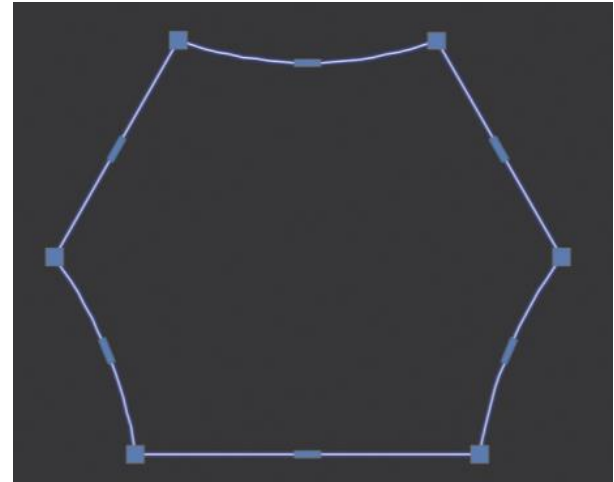

(b)

Fig. 6. a) Shape of reinforcement prepare to cutting, blue squares are points in which laser beam stops in this place, b) shape of reinforcement prepare to cutting after optimization

For HELD machines, the method of scanner cutting is used (Fig. 7). The specificity of this method is based on two laser beams, reflected by four movable mirrors, which direct the beam to the right point. The working range of one beam is inscribed in a circle with a radius of $800 \mathrm{~mm}$ and a maximum angle of $37^{\circ}$. The laser beam with mirrors only moves in the machine $x$ axis from 0 to $2550 \mathrm{~mm}$ (in its width). The focus area of the laser beam is $1.8 \mathrm{~mm}^{2}$. With this type of machine, the cutting is continuous, thanks to which the laser beam cuts much more efficiently and faster than the aforementioned Lancet laser. As a result of continuous cutting, many edges can be rounded, but they are microscopic fillets so that they do not affect the functionality of the entire airbag. 


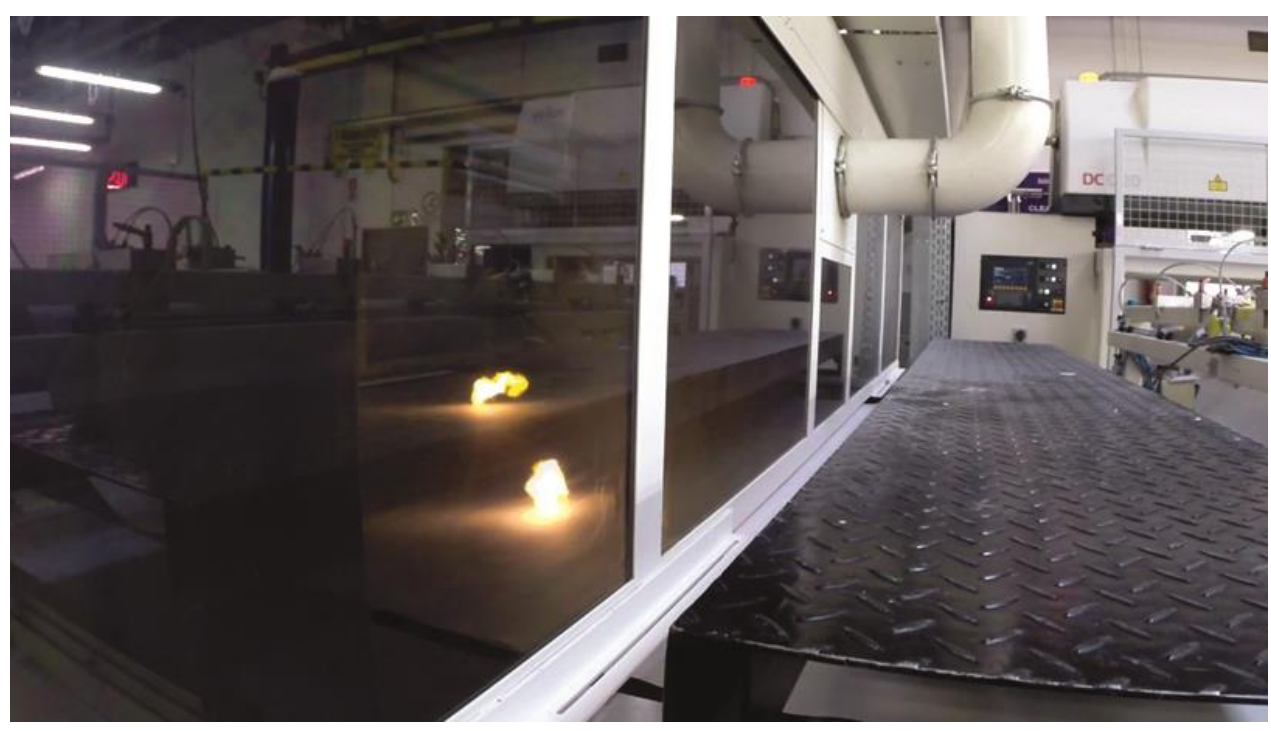

Fig. 7. Machine HELD scanner method cutting

The main task of setting the correct parameters that define laser cutting is to obtain the optimum between maximum efficiency (cutting speed) and the accuracy of cut components. The main parameter used to cut out cushion elements is the specific laser power in the watt/meter/second dimension. This is a unit developed by cutting engineers at Autoliv. To calculate the specific power value, you need: laser power, selected appropriately for the given material and the number of layers cut out, based on many years of knowledge and experience, divided by two variables, which are: the speed of the table on which the material lies and the speed with which the manipulators move the laser beam (this is the result of the surface of the cut elements). Too low set value may cause material undercuts, especially in the initial cutting phases. When the parameter value is too high, excessive melting of the material may occur, which completely disqualifies the cut element from its further use. Table I presents examples of laser beam cutting parameters for different varieties of 470dtex material used for airbag components, using the FATBOY 1000 laser plotter method, by LANCET, with a capacity of $2.5 \mathrm{~kW}$. The smaller values, given in Table

are close to optimal, while an increase in parameter values causes excessive melting of the fabric. The laser beam moves in the $x-y$ plane and the material moves in the $x$-axis direction. The material's feed rate corresponds to the speed of the laser beam.

Table I. Laser cutting an example parameters of fabric 470dtex

\begin{tabular}{|c|c|c|c|}
\hline L.p. & Material designation & $\begin{array}{c}\text { Specific power, } \\
\mathrm{W} / \mathrm{m} / \mathrm{s}\end{array}$ & $\begin{array}{l}\text { Speed of the laser } \\
\text { beam, } \mathrm{mm} / \mathrm{s}\end{array}$ \\
\hline \multirow{2}{*}{1} & \multirow{2}{*}{ 470dtex, uncoated with silicone } & 300 & 28 \\
\hline & & 1000 & 2 \\
\hline \multirow{2}{*}{2} & \multirow{2}{*}{ 470dtex, double woven, covered with silicone $25 \mathrm{~g}$} & 300 & 28 \\
\hline & & 1000 & 2 \\
\hline \multirow{2}{*}{3} & \multirow{2}{*}{ 470dtex, covered with silicone $70 \mathrm{~g}$} & 400 & 20 \\
\hline & & 1000 & 2 \\
\hline
\end{tabular}

Figure 8a shows the edges of a 470dtex fabric, uncoated with silicone, cut with a laser beam at a specific power of $300 \mathrm{~W} / \mathrm{m} / \mathrm{s}$, and figure $8 \mathrm{~b}$ shows the edge of the fabric after cutting with a laser with a power

of $1000 \mathrm{~W} / \mathrm{m} / \mathrm{s}$. Photographs of the samples were taken using a scanning electron microscope (SEM), model JSM6610A (JEOL, Japan). Because the samples do not conduct electricity, they were covered with a metallic conductive layer. Samples in the holder were placed in a vacuum sputter (model 306 from Edwards (Great Britain)), they were sprayed with a thin layer of gold. The spraying was carried out by cathodic sputtering. The specific laser power of $300 \mathrm{~W} / \mathrm{m} / \mathrm{s}$ is the optimal parameter for this material, hence visible in figure 8a there is only slight melting. The sample is slightly tilted, a fragment of the fabric surface is visible from the left. However, when the laser power is too high, $1000 \mathrm{~W} / \mathrm{m} / \mathrm{s}$, large melts are visible, which cause the sticking of many layers of the material, cut simultaneously (the edge of the glued layers was photographed from the laser side). 


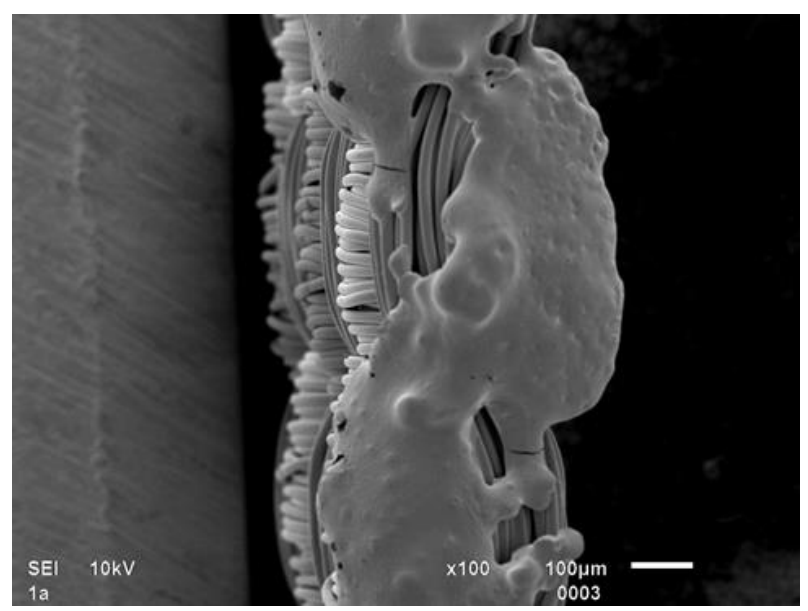

(a)

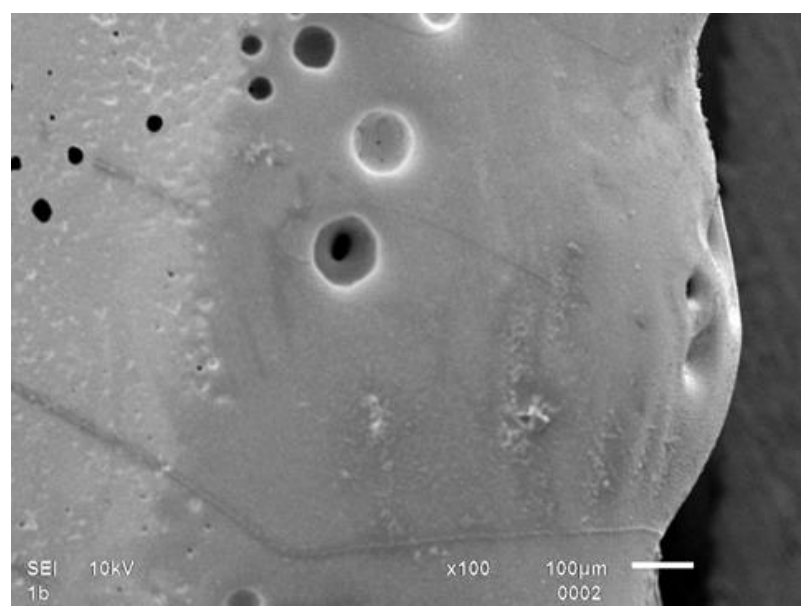

(b)

Fig. 8. Melting of fabric 470dtex silicon uncoated, view from electron microscope, SEM: a) specific power $300 \mathrm{~W} / \mathrm{m} / \mathrm{s}$, b) specific power $1000 \mathrm{~W} / \mathrm{m} / \mathrm{s}$

Laser cutting of airbag components usually takes place in the air, without shielding gas. In exceptional cases, carbon dioxide is used when cutting flammable fabrics.

\section{Control of the elements after the cutting process}

Due to the specificity of the automotive market and the special group of safety products, all specifications and quality control must be carried out with the greatest accuracy. Cut out textile elements should have a specific type of tolerance and dimensional control. Due to the material from which the airbags are made, control of the cut out elements takes place at special stands with a template and with an illuminated table (Fig. 9).

Many dimensions are standard for individual customers for whom airbags are manufactured. Depending on the company, the dimensions can be divided into standard and specific. The standard dimensions in the drawing notation are used by the designer when the dimension is oversized and less important for the function of the cushion or sewing definition in the next stages of production. Specific dimensions refer to shapes that have a significant impact on the function or sewing of the cushion. These dimensions are the lengths of the cuts that regulate the stress of the material, or the indentations on which the cushion will be mounted to the module. In the case of textiles, due to difficulties in checking dimensions, e.g. using a caliper, templates are used to which the nominal size is applied and additional shapes with the largest and smallest tolerances. In the case of cut elements, it is common practice to base the dimensions on characteristic points, which become the bases from which the shape tolerances of given parts of the element are determined.

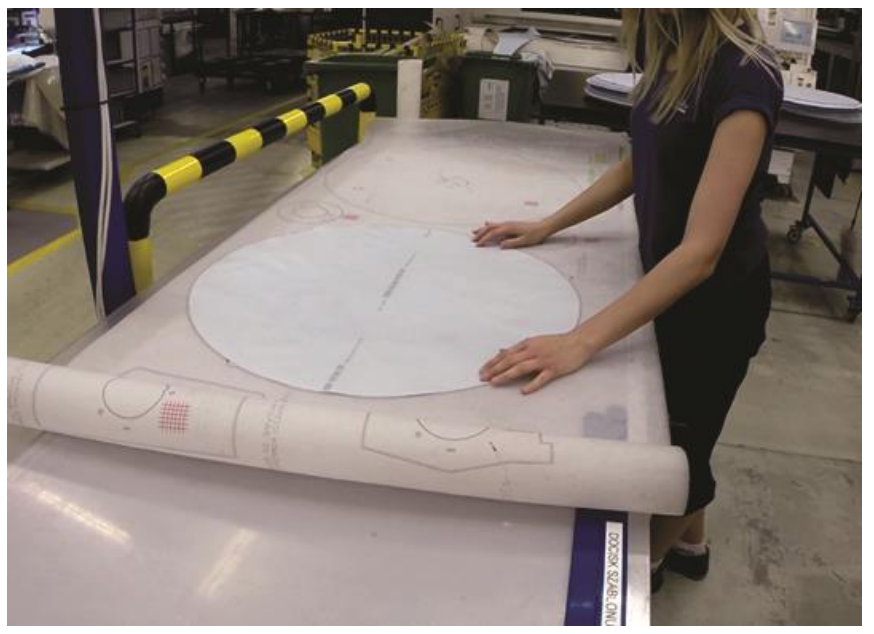

Fig. 9. Components' dimensions control after the cutting process 


\section{Summary}

1. The strength of the textile element intended for airbags can be defined by the weft and warp direction. By turning the shape of the element during the preparation of the program for laser cutting, you can get different strength parameters for the same type of material.

2. Due to the specificity of laser plotter cutting, shapes made of many lines are avoided. The aim is to simplify the shape of the airbag element, consisting of the smallest number of lines, so that the laser has as few start and stop points as possible.

3. For laser cutting of cushion elements, a specific unit is used, which is the specific power, expressed in $\mathrm{W} / \mathrm{m} / \mathrm{s}$, which correctly selected determines the optimum between the quality of cut elements and the speed at which cushion elements are cut.

4. For textile products, a specific dimension control is used where a cut-out element is checked using a template for compliance with the drawing specification.

Author Contributions: conceptualization Z.M. and J.K., methodology Z.M. and J. K., writing-review and editing, Z.M., J.K. and J.H., visualization J.K. and J.H., supervision Z. M.

Conflicts of Interest: The authors declare no conflict of interest.

\section{References}

[1] Pilarczyk J. (red.), Engineer's Guide - Welding, tom 2, WNT, Warsaw 2014.

[2] Olsen F. O., Fundamental mechanisms of cutting front formation in laser cutting, Procedings of the SPIE, 1994, vol. 2207, 402-413. DOI: 10.1117/12.184748 [Hyperlink]

[3] Steen W. M., Laser Material Processing, 3rd ed., Springer-Verlag, London, 2003.

[4] Klimpel A., Laser technologies in welding, Publishing House of Silesian University of Technology, Poland, Gliwice 2011.

[5] Klimpel A., Theoretical foundations of laser cutting of metals, Przeglad Spawalnictwa, 2012, vol. 84(6), 2-7.

[6] Kołodziejczak P., Types of laser cuttingrmicznego, Welding Technology Review, 2015, vol. 87(7), 30-33. [CrossRef]

[7] Choudhury I.A., Shirley S., Laser cutting of polumers materials: an experimental investigation, OpticsELaser Technology, 2010, vol. 42 (3), 503-508. DOI:10.1016/j.optlastec.2009.09.006 [CrossRef]

[8] Caprino G., Tagliaferri V., Maximum cutting speed in laser cutting of fibre reinforcement plastics, International Journal of Machine Toola and Manufacture, 1988, vol. 28(4), 389-398. DOI: 10.1016/0890-6955(88)90052-1 [CrossRef]

[9] Gabryś. F., Mirski Z., Granat K., Possibilities of using laser cutting in the electrotechnical industry, Biuletyn Instytutu Spawalnictwa, 2001, vol. 45(5), 161-166.

[10] Mirski Z., Granat K., Sapijaszko G., Molecular $\mathrm{CO}_{2}$ laser cutting electrical sheets metals, Przeglad Spawalnictwa, 2002, vol. 74(8-10), 139-141.

[11] Mirski Z., Granat K., Sapijaszko G., Szymkowski J., Possibilities of replacing nitrogen with air during laser cutting, Welding Technology Review, 2004, vol. 76(1), 27-30.

[12] Kwiecień J., Analysis and optimization of the laser cutting process of materials intended for car airbags, Eng. Diploma, tutor prof. Z. Mirski, Wrocław University of Science and Technology, 2019.

[13] https://www.magiapolnocy.pl/images/upload/plecionka.jpg

[14] Ion J.C., Laser Processing of Engineering Materials, Principles, Procedure and Industrial Application, Elsevier Butterwort-Heinemann, 2005.

[15] Chars L. Caristan, Laser Cutting - Guide for Manufacturing, Society of Manufacturing Engineers, Dearborn, 2004.

(C) 2019 by the authors. Submitted for possible open access publication under the terms and conditions of the Creative Commons Attribution (CC BY) license (http://creativecommons.org/licenses/by/4.0/). 